\title{
Incidence of Severe Acute Respiratory Syndrome (Covid-19) on Maintenance Hemodialysis Patients in Some Hospitals Dialysis Centers in Addis Ababa, Ethiopia
}

\author{
Sameson Taye Yirga* \\ Collage of Health Science, \\ Addis Ababa University, Addis Ababa, Ethiopia \\ Ethiopian Public Health Institute, \\ Addis Ababa, Ethiopia \\ Meron Yohannes \\ Collage of Health Science, \\ Addis Ababa University, Addis Ababa, Ethiopia
}

\author{
Bethlehem Aklilu \\ Ethiopian Public Health Institute, \\ Addis Ababa, Ethiopia
}

\begin{abstract}
Dialysis patients are highly venerable to Severe Acute Respiratory Syndrome (SARS-CoV-2) due to comorbidity conditions. In this facility-based cross-sectional study, 111 hemodialysis patients were enrolled from April, 2020 to July, 2021. Social and hospital characteristics of patient's data are abstracted from medical records, and descriptive, binominal and multinomial logistic regression was demonstrated to test association using statistical packages for social science. Among 111 hemodialysis patients Fifty three, 47.7\% (53/111) patients during the study period were under the confirmed clinical presentation of a global pandemic of SARS-CoV-2 infection. In this presented studies, inpatient hospitalization, transit of hospitals, hypertension were the most frequent clinical characteristics dependent on COVID-19 infection in dialysis patients at three referral hospitals in Addis Ababa, Ethiopia. The findings from the study indicated that dialysis patients are vournariable group of the population more likely to infect with COVID-19. Overall epidemiology of covid-19 in dialysis patients was 47\%; this indicates hospitalized dialysis is highly exposed to the current global outback. Inpatient clients and patients transferred from another hospital mostly presented comorbid conditions associated with the prevalence.
\end{abstract}

Keywords: COVID-19, Epidemiology, Hemodialysis, SARS-CoV-2,

Received: 25 November 2021; Accepted: 03 February 2022; Published: 24 March 2022

\section{INTRODUCTION}

In December 2019, it began an outbreak of Coronavirus disease (Covid19) due to the infection with a serious acute respiratory syndrome of Coronavirus 2 (Sarscov2) in Wuhan, China, and rapidly extended in other areas of China and other countries [1,2]. Dialysis patients are a very venerable group of hospitalized population and are associated with severe illness of a high mortality rate of COVID-19 [3]. Also, Patients with preexisting conditions, including those with chronic kidney disease, are at increased risk of adverse outcomes because of this infection $[4,5]$.

Over 21 million new cases were reported globally across the six WHO zones, reflecting the greatest number of weekly infections since the pandemic began. There were also about 50000 additional deaths reported. Over

\footnotetext{
${ }^{*}$ Correspondence concerning this article should be addressed to Sameson Taye Yirga, Collage of Health Science, Addis Ababa University, Addis Ababa, Ethiopia \& Ethiopian Public Health Institute, Addis Ababa, Ethiopia. E-mail: sammitaye@gmail.com

(C) 2022 The Author(s). Published by KKG Publications. This is an Open Access article distributed under a Creative Commons AttributionNonCommercial-NoDerivatives 4.0 International License.
} 
346 million confirmed cases and over 5.5 million deaths had been reported as of January 23, 2022 [6]. Already in the early phase of the COVID-19 pandemic, a high rate of acute kidney failure was described in patients with severe disease progression, with or without previous kidney diseases $[7,8,9]$.

Sero-variates are currently the main obstacle of these viruses to the ineffectiveness of the manufactured vaccine. There are no treatments available to cure those already infected with the virus. Supportive treatment, vaccination, personal protective measures, and minimizing social gatherings are the primary methods preventing the disease spread, many of whom require mechanical ventilation and other intensive care services. However, the sero-variant of the viruses is challenging for restricting the viruses incidences and it's a challenge for the currently produced vaccine [10]. There is a limited report on the prevalence of SARS-CoV-2 infection in hematological dialysis patients. This group of the hospitalized population may have an increased risk of being infected with the virus. Many patients with hemodialysis are of the age of and have certain comorbid conditions, such as cardiovascular diseases, hypertension, diabetes, and lungs, and an underlying immunistic state associated with the poorest results in patients with Covid-19 [11]. In this prospective study, we determine the prevalence of COVID-19 in 111 dialysis patients at three referral hospital dialysis centers in the city of Addis Ababa, Ethiopia. Understanding of the Transmission Dynamic prevalence of the disease to minimize the risk of transmission and acquisition of COVID-19 infection in patients with ESKD receiving in-center hemodialysis

\section{MATERIALS AND METHODS}

\section{A. Study Area}

This prospective cross-sectional study was conducted on three regional governmental referral hospitals (Minillik II hospital, st. paulos hospital, Zewditu memorial hospital) in Addis Ababa, Ethiopia. The hospitals give referral hospital services for maintenance hemodialysis service and currently serve as isolation and treatment center for global pandemic SARS- coronaviruses.

\section{B. Study design and Period}

A prospective Cross-sectional study was conducted from April / 2020 to July / 2021.

\section{Response of Participant}

From 127 hemodialysis patients taking dialysis acute and chronic patients, 111 hemodialysis patients were involved in this presented study.

\section{Population}

1) Source population: Hospitalized Maintenance hemodialysis patients under inpatient and outpatient departments from three referral hospital dialysis centers during the study period were the source population.

2) Study population: All Dialysis patients attending dialysis centers prescribed for hematological maintenance hemodialysis service were the study population.

\section{E. Study Variables}

1) Dependent variables: SARS corona virus-2 (SARSCoV-2).

2) Independent variables: Socio and clinical characteristics were determined, including age, sex, marital status, previous use of antibiotics, catheter insertion, surgical removal of kidney, arteriovenous fistula medical conditioning, and others derived from patient medical records. 3) Data collection method: Socio-demographic, clinical data, and others were extracted from patient medical records by structured checklists.

4) Data analysis and interpretation: The collected data were entry and analysis using SPSS statistical package for social science version 21 . The finding of this presented study is displayed in the table and cross-tabulation. Statistical significance was described as a p-value of less than 0.05 .

5) Ethical considerations: This study was pre-reviewed and approved by the department research and ethical committee of Addis Ababa University College of health science, IRB of Addis Ababa city health berue. Each patient was included in the study after they provided written informed consent.

\section{F. Operational Definitions}

1) Dialysis: Dialysis is a method of removing waste products and excess fluid from the blood when the kidneys no longer work properly. It often involves diverting blood to a machine to clean it.

2) SARS corona virus-2: disease has been known as "New Coronavirus 2019" or "2019nCoV". The COVID19 virus is a new virus associated with the same family of viruses as a SARS and some types of colds.

\section{RESULTS}

111 chronic dialysis patients participated in this presented study from three referral hospitals between April 2021 and July 2021. Of which 75 (67.6\%) were male, and $36(32.4 \%)$ were female. The majority of the participants were between $30-45$ (42.3\%). Fifty-three (47.7\%) maintenance hemodialysis patients during the study period were under the confirmed clinical presentation of global 
pandemic SARS-CoV-2 among 111 enrolled respondents (Table 1).

TABLE 1

SOCIO-DEMOGRAPHIC AND HOSPITAL CHARACTERIZATION AMONG PATIENTS TAKING ONGOING HEMODIALYSIS THERAPY AT THREE REFERRAL HOSPITAL DIALYSIS CENTERS IN ADDIS ABABA, ETHIOPIA

\begin{tabular}{llll}
\hline \multirow{3}{*}{ Character } & Value & N & $\%$ \\
\hline \multirow{3}{*}{ Resident } & & & \\
& Urban & 71 & $64 \%$ \\
Departmentalization & Rural & 40 & $36 \%$ \\
& Inpatient & 86 & $77.50 \%$ \\
stage of Kidney disease & Out Patient & 25 & $22.50 \%$ \\
& Acute & 9 & $8.10 \%$ \\
Hypertension & Chronic & 102 & $91.90 \%$ \\
& Yes & 86 & $78.40 \%$ \\
History of surgery & No & 25 & $22.50 \%$ \\
\multirow{4}{*}{ Arteriovenous fistula } & Yes & 80 & $72.10 \%$ \\
\multirow{3}{*}{ Failure of kidney transplantation } & No & 31 & $27.90 \%$ \\
& Yes & 19 & $17.10 \%$ \\
Catheter insertion & No & 92 & $82.90 \%$ \\
& No & 16 & $14.40 \%$ \\
Surgical removal of kidney & Yes & 1 & $85.60 \%$ \\
& No & 110 & $99.10 \%$ \\
& Yes & 1 & $0.90 \%$ \\
& No & 110 & $99.10 \%$ \\
\hline
\end{tabular}

Among 53 dialysis patients positive for SARS-CoV$2,71.6 \%(38 / 53)$ were male respondent, and patients who used dialysis therapies from an urban area and was infected with COVID-19 accounted for $67.9 \%(36 / 53)$. Patients hemodialysis patients taking dialysis 3-4 times a week were a highly exposed group than inpatient hospitalization dialysis care $84.9 \%$ (45/53). Hypertension $79.2 \%$
(42/53), surgery $67.9 \%$ (36/53), kidney stone $62.9 \%$ (33/53), transit of hospital 86.7\% (46/53), and use of medical indwelling devices $67.9 \%$ (36/53) also the dominant factors for COIVD-19 Infection in our hemodialysis patients. In addition, other clinical presentations on patients on hemodialysis therapies and infection of SARS-CoV-2 are presented in (Table 2). 
TABLE 2

PREVALENCE AND AN ASSOCIATED CLINICAL RISK FACTOR FOR THE INFECTION OF COVID-19 ON DIALYSIS PATIENTS ADDIS ABABA, ETHIOPIA

\begin{tabular}{|c|c|c|c|}
\hline Socio and Clinical Characteristics & Order & $\mathrm{N}$ & $\% \mathrm{~N}$ \\
\hline \multirow[t]{2}{*}{ Gender } & Male & 38 & $71.6 \%$ \\
\hline & Female & 15 & $28.4 \%$ \\
\hline \multirow[t]{2}{*}{ Resident } & Urban & 36 & $67.9 \%$ \\
\hline & Rural & 17 & $32.1 \%$ \\
\hline \multirow{2}{*}{ Department } & Inpatient & 23 & $43.3 \%$ \\
\hline & Outpatient & 30 & $56.7 \%$ \\
\hline \multirow[t]{2}{*}{ Outpatient } & Once & 8 & $15.1 \%$ \\
\hline & Multiple & 45 & $84.9 \%$ \\
\hline \multirow[t]{2}{*}{ Hypertension } & Yes & 42 & $79.2 \%$ \\
\hline & No & 11 & $20.8 \%$ \\
\hline \multirow[t]{2}{*}{ Diabetics } & Yes & 29 & $54.7 \%$ \\
\hline & No & 24 & $55.3 \%$ \\
\hline \multirow[t]{2}{*}{ Glomerulonephritis } & Yes & 17 & $32.0 \%$ \\
\hline & No & 36 & $68.0 \%$ \\
\hline \multirow[t]{2}{*}{ Lupus Erythromatus } & Yes & 5 & $9.5 \%$ \\
\hline & No & 48 & $90.5 \%$ \\
\hline \multirow[t]{2}{*}{ CVD } & Yes & 23 & $43.3 \%$ \\
\hline & No & 30 & $56.7 \%$ \\
\hline \multirow[t]{2}{*}{ Cyst } & Yes & 10 & $18.8 \%$ \\
\hline & No & 43 & $81.2 \%$ \\
\hline \multirow[t]{2}{*}{ Surgery } & Yes & 36 & $67.9 \%$ \\
\hline & No & 17 & $32.1 \%$ \\
\hline \multirow[t]{2}{*}{ Stone } & Yes & 33 & $62.2 \%$ \\
\hline & No & 20 & $37.8 \%$ \\
\hline \multirow[t]{2}{*}{ Transplantation } & Yes & 1 & $1.9 \%$ \\
\hline & No & 52 & $98.1 \%$ \\
\hline \multirow[t]{2}{*}{ Cancer } & Yes & 4 & $7.6 \%$ \\
\hline & No & 49 & $92.4 \%$ \\
\hline \multirow[t]{2}{*}{ HIV } & Yes & 0 & $0.0 \%$ \\
\hline & No & 53 & $100.0 \%$ \\
\hline \multirow[t]{6}{*}{ Duration } & $1-6$ month & 14 & $26.4 \%$ \\
\hline & 6-12 month & 1 & $1.9 \%$ \\
\hline & 1-3 Years & 18 & $34.0 \%$ \\
\hline & 4-6 Years & 7 & $13.2 \%$ \\
\hline & $>6$ Years & 4 & $7.5 \%$ \\
\hline & 1-month & 9 & $17.0 \%$ \\
\hline \multirow[t]{2}{*}{ Transit from other hospitals } & Yes & 46 & $86.7 \%$ \\
\hline & No & 7 & $13.3 \%$ \\
\hline \multirow[t]{2}{*}{ Use of Medical devices } & Yes & 36 & $67.9 \%$ \\
\hline & No & 17 & $32.1 \%$ \\
\hline
\end{tabular}

Key: CVD = Cardiovascular Disease, HIV = Human Immune Virus

\section{DISCUSSION}

Patients with Chronic kidney disease on dialysis face immunosuppression and a high prevalence of comorbidi- ties, raising worries that they are at an increased risk of severe coronavirus disease in 2019. The results of COVID-19 in this patient population are not well under- 
stood. There were 111 end-stage kiddy disease patients taking hemodialysis therapies were enrolled. These 53 patients had a history of COVID-19 infection, and the prevalence accounted for $47 \%$. Our finding is higher from two studies conducted in China, where the prevalence was accounted for $18.2 \%$ and $18.6 \%$, and the united kingdom, $19.6 \%[12,13,14]$. Thus, another study in Spain clarified that the prevalence of COVID-19 in hemodialysis patients was $59.5 \%$ was gathered than our results [15]. However, Variation in epidemiology between countries of COVID-19 is expected for countries. In our investigation, inpatients hospitalization, transition of patients from other hospitals, hypertension, kidney stone, and history of surgery were dependent clinical outcomes presented COVID-19 infected hemodialysis patients.

\section{CONCLUSION}

This study has a $47 \%$ prevalence of SARS-CoV-2 on hemodialysis patients in three hospital dialysis centers. This indicated that dialysis patients are highly susceptible to the current global pandemic. Inpatients, hemodialysis patients, and patient transition from other hospitals were the most common presented comorbid clinical associated risk factor presented on patients infected by the virus. A better understanding of risk factors potentially associated with infection of covid-19 is crucial for preventing the spread of the disease. Screening of the dialysis patients during admission and regular screening of dialysis patients for the development of infection, including new strain and dialysis center service disinfection and keeping of patients accordingly. The main Limitation of the result was linked sample size for strong generalizability and conclusion and required further detailed study to find out exact and more associated factor. In summary, our findings guide risk forecasting on vournariable groups of hospitalized patients and reinforce the demand for dialysis centers to remain and adopt appropriate infection control strategies to prevent coronavirus transmission.

\section{ACKNOWLEDGMENTS}

The manuscript's corresponding author would like to acknowledge all authors participating in the study.

\section{REFERENCES}

[1] W. H. Organization, "WHO COVID-19 preparedness and response progress report- 1 february to 30 june 2020," Geneva, Switzerland: World Health Organization, Tech. Rep., 2020.

[2] R. Wang, C. Liao, H. He, C. Hu, Z. Wei, Z. Hong, C. Zhang, M. Liao, and H. Shui, "COVID-19 in hemodialysis patients: A report of 5 cases," Ameri- can Journal of Kidney Diseases, vol. 76, no. 1, pp. 141-143, 2020. doi: https://doi.org/10.1053/j.ajkd. 2020.03.009

[3] N. Canpolat et al., "Covid-19 in pediatric patients undergoing chronic dialysis and kidney transplantation," European Journal of Pediatrics, vol. 181, no. 1, pp. 117-123, 2022. doi: https://doi.org/10. 1007/s00431-021-04191-z

[4] T. J. Kakkanattu, S. Sankarasubbaiyan, A. K. Yadav, M. Kundu, M. G. Bg, V. Kumar, K. Shah, and V. Jha, "Outcome and determinants of outcome of COVID-19 infection among hemodialysis patients: Findings from a national dialysis network program in India," Kidney International Reports, vol. 6, no. 5, pp. 1429-1432, 2021. doi: https://doi.org/10.1016/j.ekir.2021.03.003

[5] E. D. Weinhandl, J. B. Wetmore, Y. Peng, J. Liu, D. T. Gilbertson, and K. L. Johansen, "Initial effects of COVID-19 on patients with ESKD," Journal of the American Society of Nephrology, vol. 32, no. 6, pp. 1444-1453, 2021. doi: https://doi.org/10.1681/ ASN.2021010009

[6] W. H. Organization et al., "Covid-19 weekly epidemiological update," Geneva, Switzerland: World Health Organization, Tech. Rep., 2022.

[7] E. Hoxha, A. Suling, J. E. Turner, M. Haubitz, J. Floege, T. B. Huber, and J.-C. Galle, "COVID19 prevalence and mortality in chronic dialysis patients," Deutsches Ärzteblatt International, vol. 118, no. 11, pp. 195-196, 2021. doi: https://doi.org/10. 3238/arztebl.m2021.0160

[8] C. Clarke et al., "High prevalence of asymptomatic COVID-19 infection in hemodialysis patients detected using serologic screening," Journal of the American Society of Nephrology, vol. 31, no. 9, pp. 1969-1975, 2020. doi: https://doi.org/10.1681/ASN . 2020060827

[9] W. Shang, Y. Li, H. Li, W. Li, C. Li, Y. Cai, and J. Dong, "Correlation between laboratory parameters on admission and outcome of COVID19 in maintenance hemodialysis patients," International Urology and Nephrology, vol. 53, no. 1, pp. 165-169, 2021. doi: https://doi.org/10.1007/ s11255-020-02646-0

[10] S. Alizon, S. Haim-Boukobza, V. Foulongne, L. Verdurme, S. Trombert-Paolantoni, E. Lecorche, B. Roquebert, and M. T. Sofonea, "Rapid spread of the SARS-CoV-2 delta variant in some french regions, june 2021," Eurosurveillance, vol. 26, no. 28, p. 2100573, 2021. doi: https://doi.org/10.2807/ 1560-7917.ES.2021.26.28.2100573 
[11] T. A. Ikizler, "COVID-19 and dialysis units: What do we know now and what should we do?" American Journal of Kidney Diseases, vol. 76, no. 1, pp. 1-3, 2020. doi: https://doi.org/10.1053/j.ajkd.2020. 03.008

[12] A. M. Valeri, S. Y. Robbins-Juarez, J. S. Stevens, W. Ahn, M. K. Rao, J. Radhakrishnan, A. G. Gharavi, S. Mohan, and S. A. Husain, "Presentation and outcomes of patients with ESKD and COVID19," Journal of the American Society of Nephrology, vol. 31, no. 7, pp. 1409-1415, 2020. doi: https://doi.org/10.1681/ASN.2020040470

[13] Y. Ma, B. Diao, X. Lv, J. Zhu, C. Chen, L. Liu, S. Zhang, B. Shen, and H. Wang, "Epidemiological, clinical, and immunological features of a cluster of COVID-19-contracted hemodialysis patients,"
Kidney International Reports, vol. 5, no. 8, pp. 1333-1341, 2020. doi: https://doi.org/10.1016/j.ekir. 2020.06.003

[14] R. W. Corbett, S. Blakey, D. Nitsch, M. Loucaidou, A. McLean, N. Duncan, D. R. Ashby et al., "Epidemiology of COVID-19 in an urban dialysis center," Journal of the American Society of Nephrology, vol. 31, no. 8, pp. 1815-1823, 2020. doi: https://doi.org/10.1681/ASN.2020040534

[15] M. Albalate et al., "High prevalence of asymptomatic COVID-19 in hemodialysis. daily learning during first month of COVID-19 pandemic," Nefrología (English Edition), vol. 40, no. 3, pp. 279-286, 2020. doi: https://doi.org/10.1016/j.nefroe.2020.06. 013 